\title{
A New Case of Consensual Decision: Collective Movement in Earthworms
}

\author{
Lara Zirbes ${ }^{*}$, Jean-Louis Deneubourg ${ }^{\dagger}$, Yves Brostaux $^{\ddagger} \&$ Eric Haubruge ${ }^{*}$ \\ * Functional and Evolutionary Entomology, Gembloux Agro-Bio Tech, University of Liège, Gembloux, Belgium \\ ${ }^{\dagger}$ Unit of Social Ecology, Université libre de Bruxelles, Campus Plaine - CP 231, Brussels, Belgium \\ * Applied Statistics, Computer Science and Mathematics, Gembloux Agro-Bio Tech, University of Liège, Gembloux, Belgium
}

\begin{abstract}
Collective movements are reported for many species from microorganisms to humans. But except for a few soilinhabiting species, intra-specific interactions in soil are poorly studied. Some intra-specific interactions occur in earthworms. Most of them are negative, concerning parameters like the rate of survival, maturation, food ingestion or growth. Virtually nothing is known about collective movement in earthworms that represent the dominant biomass of the soil. This study, the first one on annelids, highlights a consensual decision phenomenon based only on contact between followers. Using an olfactometer set-up and modelling, we show that earthworms Eisenia fetida influence each other to select a common direction during their migration. Experiments in a binary choice test showed that contacts between individuals are responsible for collective movement. This coordination in movement could allow earthworms to benefit from forming clusters. The resulting local higher densities, enhancing individual survival and favouring the cooperation, may be at the origin of Allee effects reported for these species.
\end{abstract}

\section{Introduction}

Unlike inter-specific interactions (Bonkowski et al. 2000; Salmon \& Ponge 2001; Pizl \& Novakova 2003; Rasmann et al. 2005), intra-specific interactions in different spheres of soil like drilosphere and detritusphere are less studied, except for ants and termites (Jouquet et al. 2003; Mikheyev \& Tschinkel 2004; Tschinkel 2005). Here, we have explored the influence of intra-specific interactions in a particular soil-inhabiting group: the earthworms. Indeed, earthworms represent up to $70 \%$ of soil biomass (Lee 1985) and are major representatives of drilosphere and detritusphere (Brown et al. 2000). The drilosphere is the soil area directly influenced by earthworms whereas detritusphere corresponds to the litter system at soil surface (Brown et al. 2000). A recent review shows that intra-specific interactions have been studied in 15 lumbricid species. Intra-specific reactions are strongly associated with density and in most cases intra-specific interactions associated with high density have a negative influence on conspecifics like a diminution in rates of growth and maturation, survival or reproduction. Frequently, the growth rate of a population declines with increasing density (Uvarov 2009). Moreover, density seems to be an important parameter to regulate population dynamics in Eisenia fetida (Kammenga et al. 2003).

Eisenia fetida belongs to the epigeic earthworms group (Bouché 1977). This ecological category lives on or near the soil surface, typically in the litter layers of forest soils and does not burrow (Lee 1985; Edwards \& Bohlen 1996; Römbke et al. 2005). Due to their surface proximity, this ecological category of earthworms is under high predation and so has a short life cycle depending principally on population density and environmental temperature (Lee 1985; Edwards \& Bohlen 1996). This life cycle (at $25^{\circ} \mathrm{C}$ ) is characterized by the production of one or more cocoons after mating, $20 \mathrm{~d}$ later cocoons hatch and 2-10 hatchlings born. These hatchlings become mature (with clitellum) 4-6 wk later (Lee 1985). Epigeics feed on litter and/or the attached microflora and ingest little soil. A few species, best known among them E. fetida and Eisenia andrei, are specialists in places with high organic matter content (Lee 1985).

Like some other lumbricids, E. fetida lives in patchy distribution (Reinecke \& Viljoen 1990; Boag et al. 1994; Uvarov 2009). The spatial heterogeneity of the population depends on food distribution and abiotic parameters also on intra-specific interactions, including inter-attraction. Like in other animal species, inter-attraction could generate an Allee effect (Courchamp et al. 2008) and collective movement (Krause \& Ruxton 2002). It is recognized that individuals of many species may benefit from the presence of conspecifics. The Allee effect is 
defined as a positive relationship between any component of individual fitness and either numbers and density of conspecifics (Stephens et al. 1999).

Collective movement is sometimes observed in earthworm populations. They evade unfavourable environmental conditions like flooded soil and low oxygen tension or seek new habitats (Edwards \& Bohlen 1996).

Occasionally, the number of earthworms migrating is especially significant (Edwards \& Bohlen 1996; Buhl et al. 2006), suggesting that social cues may be responsible for collective movement. Chemical and/or physical 'communication' could occur in earthworms. For example, noxious stimulation, like the electric shock of an earthworm, elicits secretion acting as an alarm pheromone, i.e. an earthworm contacting such secretions escapes more rapidly from the area than from a clean area (Schmidt 1955; Ressler et al. 1968; Jiang et al. 1989). Indeed, metabolites of individual activity perceived by conspecifics acting as alarm pheromones have been reported in different species of earthworms (Ratner \& Boice 1971; Rosenkoetter \& Boice 1975). Lumbricus terrestris may often find its partners by a trail-following behaviour and use contact to choose a sexual partner during the premating (Nuutinen \& Butt 1997). While some studies investigate the influence of intra-specific interaction on earthworms' life parameters (survive, growth, reproduction, cocoons hatchability) (Domiguez et al. 1997; Uvarov \& Scheu 2004; Uvarov 2009), no research has investigated collective movement in earthworms and the underpinning mechanisms.

In this study, we observed earthworms' behaviour in an olfactometer set-up in order to establish the degree of potential collective movement in E. fetida. Further, we investigated whether chemical (trail-following) and physical (contact) cues are involved in collective movement in earthworms.

\section{Materials and Methods}

\section{Eisenia Fetida Rearing}

The earthworms (E. fetida) used in this study come from vermicomposting Ouroboros s.a. (Gembloux, Belgium). They are reared in PVC boxes (42 cm long, $30 \mathrm{~cm}$ wide and $10 \mathrm{~cm}$ high) filled with universal compost DCM ${ }^{\circledR}$ (De Ceuster Meststoffen s.a., Grobbendonk, Belgium). This compost is changed every 2 mo and cocoons and hatchling earthworms are sorted out in order to be released in a new box with fresh compost. Boxes were kept at a temperature of $23 \pm 1^{\circ} \mathrm{C}$. For the experiments, only mature earthworms (with a clitellum) were used.

\section{Binary Choice Experiments}

Binary choice experiments remain one of the easiest ways to study collective decision making and to analyse the relation between individual behaviour and collective decision making (Jeanson \& Deneubourg 2009). The distribution of the number of individuals among two alternatives may be different according to the species and situation: it can vary from an equidistribution to a strong difference between the number of individuals choosing either direction. Two experimental set-ups were used for binary choice experiments: (1) olfactometer assays and (2) contact assays.

\section{Olfactometer assays}

The behaviour of earthworms was tested in a two-arm olfactometer consisting of a central PVC chamber $(20 \mathrm{~cm}$ $\times 20 \mathrm{~cm} \times 20 \mathrm{~cm}$ ) with two equally distributed side arms $(9 \mathrm{~cm}$ in diameter, $18 \mathrm{~cm}$ long) (Fig. 1a). These arms were connected to the central chamber and $25 \mathrm{~g}$ of the same food source (sheep manure) was placed in the extremity of each arm. For each experiment, the entire system was filled with moist universal compost DCM $^{\circledR}$ (76\% humidity content). An approximately $25 \mathrm{~g}$ sample of moist compost was dried at $105^{\circ} \mathrm{C}$ for $48 \mathrm{~h}$ to determine the moisture content ( 15 repetitions were realized). Forty earthworms, E. fetida, were released in the centre of the central chamber. Twenty-four hours after being released, the arms of each olfactometer were disassembled from the central chamber, the compost from each arm was placed in containers and the earthworms were counted. Thirty repetitions were conducted, the olfactometer was washed with distilled water and compost was replaced between each repetition.

\section{Contact/trail assays}

A diamond-shaped set-up ( $15 \mathrm{~cm}$ long, $10 \mathrm{~cm}$ wide, $5 \mathrm{~cm}$ high) with start and end point $(3 \mathrm{~cm}$ long, $1.5 \mathrm{~cm}$ wide, $5 \mathrm{~cm}$ high) (Fig. 1b) was used to study contact and trail-following for E. fetida mature earthworms. This set-up was filled with $56.25 \mathrm{~cm}^{3}$ of moist universal compost $\mathrm{DCM}^{\circledR}$ (76\% humidity content). Observations were made under red light in order to not to disturb the earthworms (Lee 1985). 
This experimental set-up was emptied, washed with distilled water and compost was replaced between each repetition.

In the trail-following assays, two experiments were performed. In the first experiment, one earthworm was placed on the start point set-up and was free to choose a branch. It was then removed when it reached the end point with a food source ( $2 \mathrm{~g}$ of sheep manure). After that, a second earthworm was released at the start point and its choice was observed. This experiment was repeated 45 times. The two possibilities for earthworms were to move in the same direction or not. In the second experiment, five earthworms (one after the other) were forced to move on the same branch set-up by blocking the other branch with a PVC piece and the choice of the sixth one was recorded. The experiment was repeated 10 times.

In contact trial tests, two earthworms were simultaneously placed at the start point of the set-up and both selected directions were observed and recorded when they reached the end point filled with food resources ( $2 \mathrm{~g}$ of sheep manure). This experimentation was repeated 45 times. Two results could be observed: (1) both earthworms on the same direction (right or left) and (2) one earthworm on the left and one on the right.

Fig. 1: Experimental set-ups. (a) Two-arm olfactometer to earthworms' cooperation assays. A = central chamber, $B=$ arms of the olfactometer. (b) Behavioural set-up to trail-following and contact bioassays. Start point $=$ point where earthworms were placed at the beginning of the experiments, food source $=$ destination of earthworms.

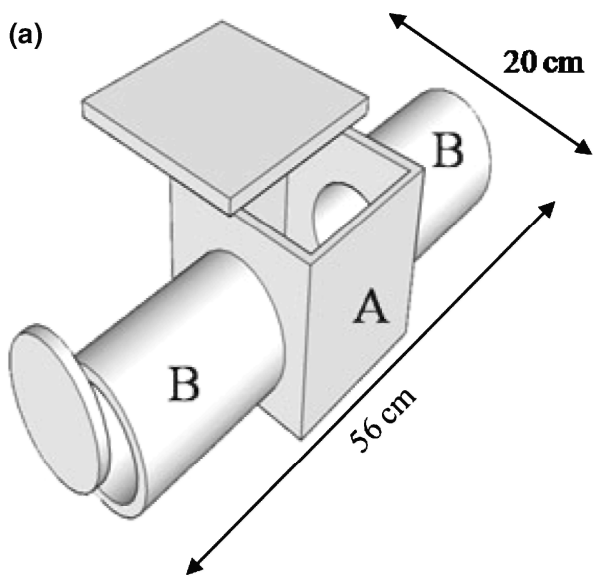

(b)

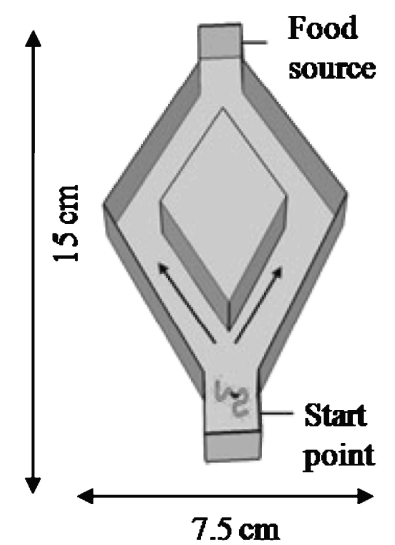

\section{Statistical Analyses}

A chi-square Goodness-of-fit test (Minitab ${ }^{\circledR}$ v15.0, State College, PA, USA; $\mathrm{n}=30, \alpha=5 \%, 1 \mathrm{df}$ ) was used to compare distribution of the number of earthworms in both arms (vs. the central chamber) of the two-arm olfactometer and a binomial distribution. 
Statistical differences in direction selection by earthworms were determined by fitting a constant probability generalized linear model to the data. The generalized linear model was used to take into account the non-constant number of earthworms in both arms for the 30 repetitions of the test. Under the assumption of independence of choices of the individual worms, the residual deviance of this model should follow a chi-square distribution with $29 \mathrm{df}$ (Faraway 2006). An overdispersion test was then realized to check this assumption (R 2.7.1). To graphically display the results of this test, the observed proportions of earthworms on the left branch were reduced by their mean and scaled by their standard deviation, allowing for comparison. Under the hypothesis of independence of movements, this reduced distribution should tend to a reduced normal distribution by Moivre's theorem. So the figure obtained superimposes the density of reduced observed earthworms' proportions in the left arm on the corresponding reduced normal distribution.

For trail-following assays and contact trial tests, a chi-square Goodness-of-fit test (Minitab® v15.0; $\mathrm{n}=45, \alpha=$ $5 \%, 1 \mathrm{df}$ ) was used to compare theoretical distribution (respectively, 50\%-50\% for each possibility) and observed distribution.

\section{Simulation}

Simulation was used to determine whether behaviour observed between two earthworms in contact/trail assays could explain behaviour observed between 40 earthworms in the two-arm olfactometer.

At the start of a simulation, all the individuals (N) are assumed to be in the central chamber. For each simulation, $\mathrm{N}$ earthworms were given the choice of leaving the central chamber and choosing between two identical branches. The individual probability of leaving the central chamber $(\mathrm{P})$ was calculated to be 0.84 (see Results section for details) using the results of two-arm olfactometer assays. The individual decision of leaving the chamber was checked and depends on the comparison between $\mathrm{P}$ and a random number sampled from a uniform distribution between 0 and 1 . If its value is $\leq \mathrm{P}$, the individual leaves the chamber and its selection of direction is tested. $\mathrm{P}_{\mathrm{L}}$ and $\mathrm{P}_{\mathrm{R}}$ are, respectively, the probability of choosing the left or right branch. If the value of a second random number is $\leq \mathrm{P}_{\mathrm{L}}$ the individual chooses the left branch. If not, it takes the opposite direction. For the first individual leaving the chamber, $\mathrm{P}_{\mathrm{L}}=\mathrm{P}_{\mathrm{R}}=0.5$ (the two branches of the experimental set-up are identical).

For the others, $\mathrm{P}_{\mathrm{L}}=\mathrm{Q}\left(\mathrm{P}_{\mathrm{R}}=\mathrm{Q}\right)$ if its predecessor chooses the left (right) branch, $\mathrm{Q}$ being the probability of following its predecessor and choosing the same direction. $\mathrm{Q}=0.5$ corresponds to a random choice (no social influence). In case of social interaction, $\mathrm{Q}>0.5$ corresponds to a social attraction and $\mathrm{Q}<0.5$ corresponds to the situation where the earthworm prefers to take the opposite direction to its predecessor. The contact trial test where two earthworms were simultaneously placed in the set-up provided the Q experimental value.

The percentage of earthworms that chose the winner branch was counted at the end of the simulation. For both hypotheses (with or without social interaction), the possible outcome of the average from 30 experiments and their distribution was calculated 1000 times.

The simulation was also used to estimate the mean number of earthworms selecting the winner branch as a function of the number of earthworms choosing one direction and of the value of Q.

\section{Results}

Figure 2a shows the distribution of the total number of earthworms leaving the central chamber of the olfactometer. This distribution was compared to a binomial theoretical distribution which should be observed when no interaction exists between individuals. Among the 1200 tested earthworms (40 earthworms $\times 30$ replicates), 1005 left the central chamber. The theoretical binomial distribution was then generated with an estimated probability of leaving of $0.84(1005 / 1200)$ that an individual leaves the central chamber. In this case, experimental distribution was not different from the theoretical distribution (chi-square Goodness-of-fit test, $\chi_{4}{ }^{2}$ $=4.09, \mathrm{p}=0.394)$. The results were not biased by experimental set-up: at the end of 30 repetitions, the number of earthworms was not significantly different in both arms of the olfactometer (right $=521$, left $=484)$.

The generalized linear model showed that the distribution of the choice of one arm (number on the left arm) was significantly different (Deviance test, $\chi_{29}{ }^{2}=71.05, \mathrm{p}<0.001$ ) from the binomial distribution with a trend towards statistical overdispersion. These results strongly imply dependence between the choices of earthworms (Fig. 2b). These results show that earthworms moving out of the central chamber influence the directional choice of other earthworms, but not their propensity to leave the central chamber. 
Fig. 2: Experimental results. (a) Observed (grey) and theoretical (white) distributions of Eisenia fetida earthworms in both olfactometer arms. NS indicates no significant difference between observed and expected distribution. (b) The comparison of theoretical (discontinuous stroke) and experimental distributions (continuous stroke) of the proportion of earthworms on the left olfactometer arm shows an excess of off-centre proportions which indicate non-independent choice in earthworms' movements. Bars at the bottom of the chart represent reduced observed proportions that were used to calculate the density of probability. ***Significant difference between observed and expected distributions at $p<0.001$.
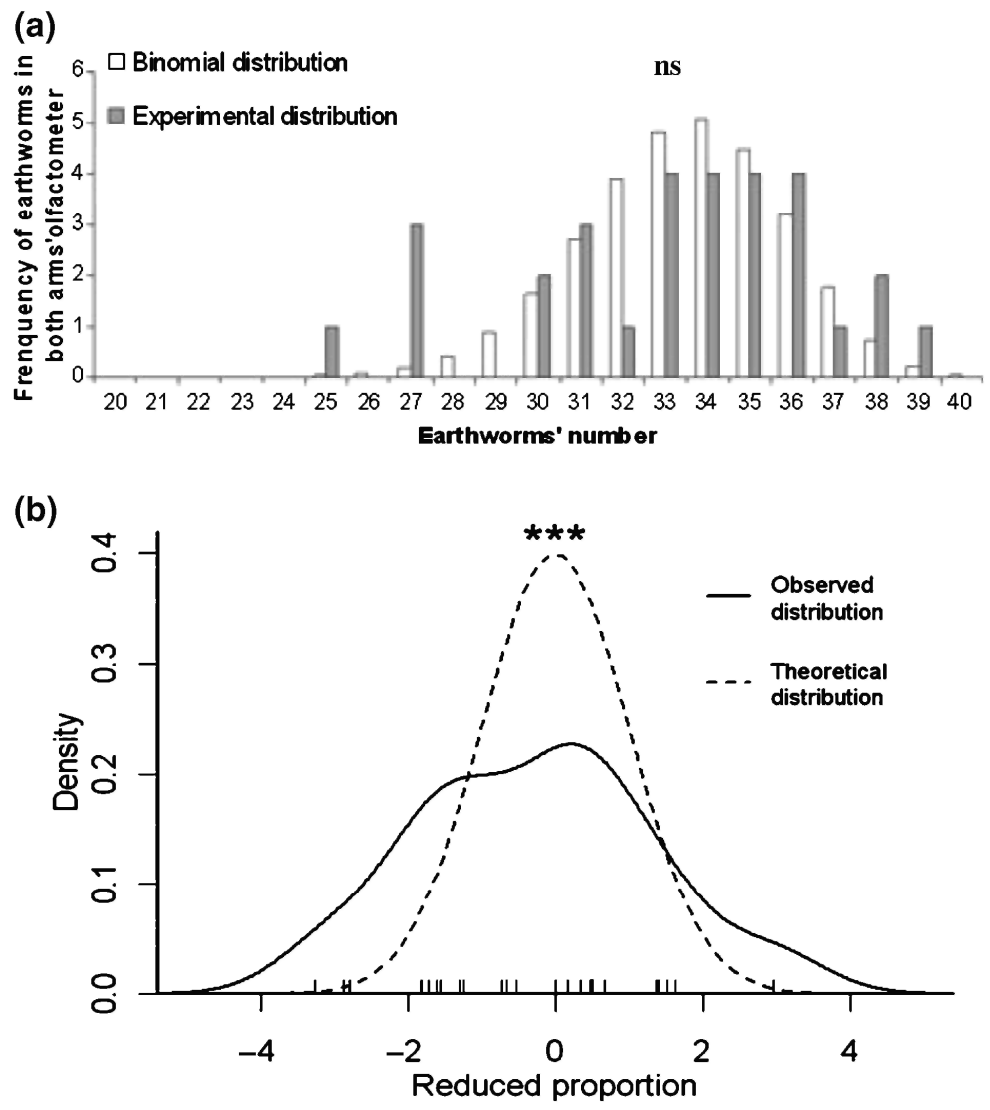

To determine whether earthworms follow a conspecific trail, two behavioural trial tests were used. In the first trail-following test, one E. fetida $(\mathrm{n}=45)$ earthworm was placed at the starting point and was free to choose a direction (right or left). In this assay, $46.7 \%$ of the earthworms chose the same direction as the previous one and $53.3 \%$ did not. The results were not significantly different from 50\%-50\% (chi-square Goodness-of-fit test, $\chi_{1}^{2}=$ $0.2, \mathrm{p}=0.655)$. The trail-following test was conducted in the same conditions as previously. However, five $E$. fetida earthworms $(\mathrm{n}=10)$ were forced to move in the same direction (right or left) and the direction of the sixth earthworm was recorded. In this case, five earthworms followed their predecessors and five earthworms did not. These results indicate that the earthworms did not follow a conspecific trail by olfactory orientation.

To establish whether or not contact between E. fetida earthworms influences E. fetida interaction, two earthworms $(n=45)$ were simultaneously placed at the starting point (Fig. 1b). In this experiment $69 \%$ moved together while $31 \%$ of the pairs did not select the same direction. There was a significant difference (chi-square Goodness-of-fit test, $\chi_{1}^{2}=7.53, p=0.006$ ) between the experimental and theoretical (i.e. absence of any interaction) distributions (Fig. 3). The contact between earthworms strongly influences the directional choice of the follower. Indeed, the probability of following the predecessor (Q) is estimated to be 0.7 . 
Fig. 3: Observed (dark grey) and theoretical (light grey) distributions of the proportion of earthworms which select a direction together in behavioural bioassays when two earthworms were in contact at the start of the experiment. *Significant difference between observed and theoretical distributions at $p<0.05$.

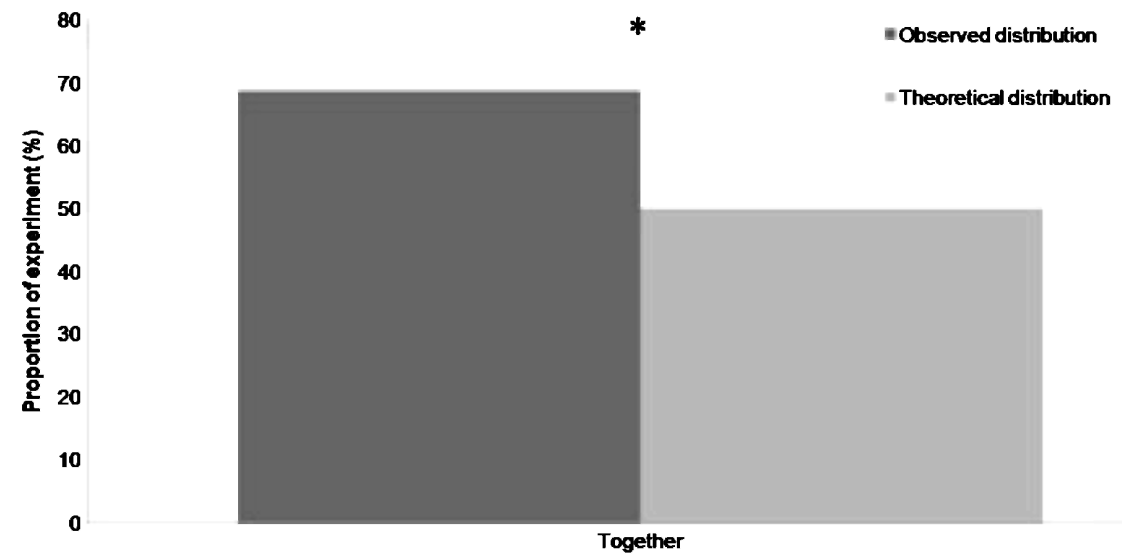

Fig. 4: Simulation results. (a) Results for parameter values $p=0.84, Q=0.5$ and $Q=0.7$. These distributions of the mean number of earthworms in the winner branch of the two-arm olfactometer are generated after 1000 runs of 30 replications. (b) The curves show the average number of earthworms in the winner branch for different earthworm numbers and for different probabilities to follow its predecessor. In this case, the probability to leave the central chamber was equal to $1(p=1)$.

(a)

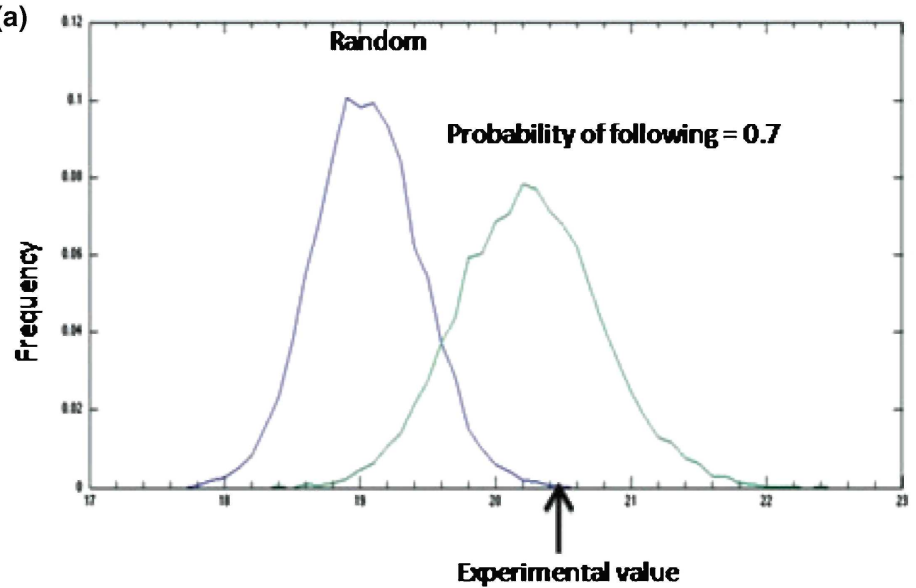

Mean number of earthworms choosing the winner branch for one group of 30 replicates

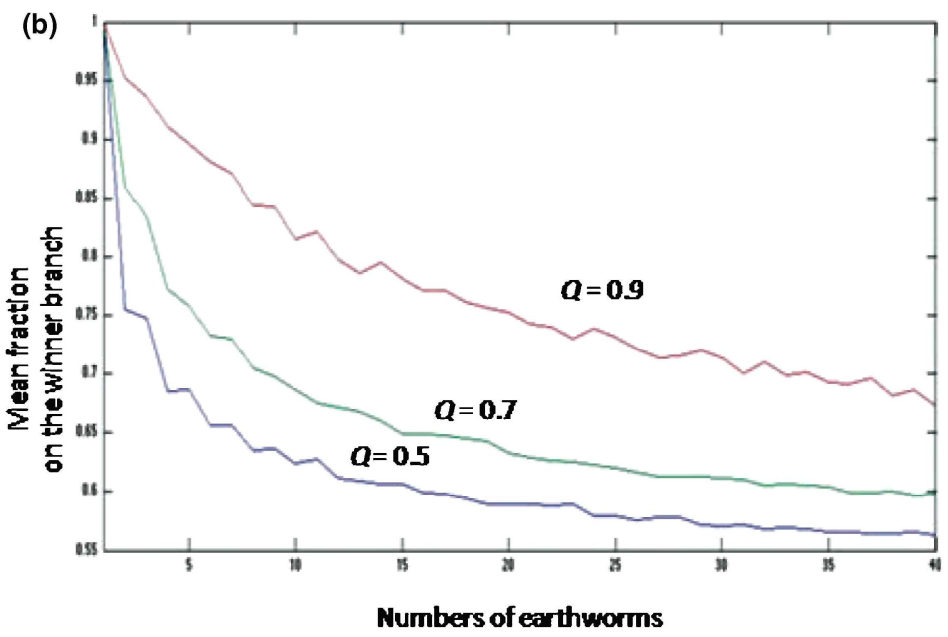


A simple model shows that such probability of following generates the earthworm distribution among both branches when groups of 40 individuals were tested in the two-arm olfactometer. The number of earthworms selecting the winner branch was counted at the end of the simulation. The mean distribution of 30 experiments average was calculated (Fig. 4a). The probability of obtaining an equivalent average number of earthworms on the chosen branch from experimental data $(\bar{x}=20.27)$ was maximal with the $Q$ value resulting from contact trial tests $(\mathrm{Q}=0.7)$. With weaker social interaction $(\mathrm{Q}<0.6)$, the probability of obtaining an equivalent average number of earthworms on the chosen branch from experimental data was $<0.05$ and without social interaction the probability was slight $(=0.002)$. Our simulation has shown that contact explains collective movement observed between $E$. fetida earthworms. We have also shown that the average fraction of earthworms on the winner branch decreases as the number of earthworms increases for each Q value (Fig. 4b) (See Supporting Information for equation development). This diminution was abrupt for groups of 15 earthworms, but was more gradual for larger number of tested earthworms. So the higher the number of tested earthworms in the olfactometer, the greater the symmetry between the two olfactometer arms. These results highlight the fact that the mechanism worked best for small numbers of earthworms.

\section{Discussion}

Individual earthworm propensity to leave the central chamber was not dependent upon the number of earthworm that already left the central chamber. However, the experimental distribution (see Fig. 2a) was slightly bimodal due to peaks at 25 and 27, suggesting that the earthworm probability of leaving the central chamber was weakly influenced by the departure of conspecifics (Sempo et al. 2009).

We have demonstrated the E. fetida earthworms' cooperative capacity to select direction through contact among individuals. To our knowledge this is the first example of collective orientation in animals based only on contact between followers and also the first one of collective movement in annelids. It is well known that earthworms use tactile receptors on the surface body for thigmotactic responses (Lee 1985). Moreover, earthworms have chemoreceptors principally on the prostonium or on the buccal epithelium (Edwards \& Bohlen 1996). Contact with surface secretion of earthworms has a quieting influence on other earthworms of the same species, i.e. when one or more earthworms settled down anywhere the others stopped more readily in that place (Loeb 1973).

Earthworms E. fetida were able to perceived pheromone, such as alarm pheromone (Ressler et al. 1968; Rosenkoetter \& Boice 1975; Jiang et al. 1989), however pheromone following did not seem to be a mechanism used by E. fetida to move together. Trail-following could have an effect on earthworms' behaviour if the number of earthworms forced to move in the same direction was increased. This possibility should be explored further in future experimental research. Nevertheless, it is unlikely that, in natural environment, more than five earthworms follow. Collective movement mediated by chemical and/or physical contact has been observed in a large diversity of invertebrates (Costa 2006; Simpson et al. 2006; Huang et al. 2007). Eisenia fetida seems to use the contact strategy to collectively move with conspecifics. In our experimental conditions, only the predecessor influenced the follower choice. So any amplification process was observed. However, we did not exclude an amplification process if the flow of earthworms increased.

Intra-specific interactions have been observed in some other ecological group of earthworms. Positive interactions exist between hatchlings and conspecific adults during the development in anecic species (Lowe \& Butt 2002; Grigoropoulou et al. 2008). Physical contacts occur and influence the burrowing behaviour in anecic species, but not in endogeic species (Capowiez 2000). Our observations showed that intra-specific interactions were also present in epigeic species. But some future experiments are necessary to confirm collective movement in other ecological categories.

The collective movement could also be a mechanism leading earthworms to cluster. The enhancement of chemical defences could be one advantage of clustering (Wertheim et al. 2005). For the earthworm E. fetida, the defensive line comprises cells floating in coelomic fluid and humoral effector proteins secreted into the coelomic fluid. This body fluid is known to contain a variety of cytolytic and bacterial activities to combat potential soil pathogens (Bruhn et al. 2006). Eisenia fetida are also the prey of terrestrial flatworms. Eisenia fetida secretes yellow coelomic fluid in response to flatworm, Bipalium adventitium, attack producing an aversive response by the flatworm thus increasing the survival rate of this earthworm species (Fiore et al. 2004). Aggregations of earthworms could produce greater amounts of defensive compounds thus providing better resistance to soil pathogens and predators. Such cooperative defence behaviour would be particularly vital when only some earthworms are under high predation pressure. The resistance to bad environmental conditions (flooded soil, dry soil) could be a second advantage of clustering (Edwards \& Bohlen 1996). 
These results strongly suggest a positive relationship between individual fitness and density and may explain that an Allee effect is present in earthworms (Courchamp et al. 2008).

\section{Acknowledgements}

We thank the staff member of the Functional and Evolutionary Entomology Unity for their continual support; D. Conoir for his technical assistance; and the Ouroboros s.a. society for E. fetida earthworms.

We are grateful to Gary Felton (Pennsylvania State University) for his valuable comments on the manuscript.

Lara Zirbes was financially supported by a $\mathrm{PhD}$ grant from the Fonds pour la formation à la Recherche dans l'Industrie et l'Agriculture (FRIA), Belgium.

\section{Authors' Contributions}

L.Z. conceptually designed and coordinated all experimental works, conducted most measurement and wrote the manuscript. E.H. has supervised the study. J.L.D. and Y.B. made all modelling, simulation and statistical analyses.

\section{Literature Cited}

Boag, B., Legg, R. K., Neilson, R., Palmer, L. F. \& Hackett, C. A. 1994: The use of Taylor's Power Law to describe the aggregated distribution of earthworms in permanent pasture and arable soil in Scotland. Pedobiologia 38, 303-306.

Bonkowski, M., Griffin, B. S. \& Ritz, K. 2000: Food preferences of earthworms for soil fungi. Pedobiologia 44, 666-676.

Bouché, M. B. 1977: Strategies lombriciennes. In: Soil Organism as Components of Ecosystems (Persson, T. \& Lohm, U., eds). Ecological Bulletins, Stockholm, pp. 122-132.

Brown, G. G., Barois, I. \& Lavelle, P. 2000: Regulation of soil organic matter dynamics and microbial activity in the drilosphere and the role of interactions with other edaphic functional domains. Eur. J. Soil Biol. 36, 177-198.

Bruhn, H., Winkelmann, J., Andersen, C, Andrä, J. \& Leippe, M. 2006: Dissection of the mechanisms of cytolytic and antibacterial activity of lysenin, a defence protein of the annelid Eisenia fetida. Dev. Comp. Immunol. 30, 597-606.

Buhl, J., Sumpter, D. J., Couzin, I. D., Hale, J., Despland, E., Miller, E. \& Simpson, S. J. 2006: From disorder to order in marching locusts. Science 312, 1402-1406.

Capowiez, Y. 2000: Differences in burrowing behaviour and spatial interaction between the two earthworm species Aporrectodea nocturna and Allolobophora chlorotica. Biol. Fertil. Soils 30, 341-346.

Costa, J. T. 2006: The Other Insect Societies. Cambridge Univ. Press, Cambridge.

Courchamp, F., Berec, L. \& Gascoign, J. 2008: Allee Effects in Ecology and Conservation. Oxford Univ. Press, Oxford, UK.

Domiguez, J., Briones, M. J. I. \& Mato, S. 1997: Effect of the diet on growth and reproduction of Eisenia andrei (Oligochaeta, Lumbricidae). Pedobiologia 41, 566-576.

Edwards, C. A. \& Bohlen, P. J. 1996: Biology and Ecology of Earthworms. Chapman and Hall, London.

Faraway, J. J. 2006: Extending the Linear Model with R: Generalised Linear, Mixed Effects and Non Parametric Regression Models. Chapman and Hall/CRC, Boca Raton.

Fiore, C, Tull, J. L., Zehner, S. \& Ducey, P. K. 2004: Tracking and predation on earthworms by the invasive terrestrial planarian Bipalium adventitium (Tricladida, Platyhelminthes). Behav. Processes 67, 327-334.

Grigoropoulou, N., Butt, K. R. \& Lowe, C. N. 2008: Effects of adult Lumbricus terrestris on cocoons and hatchlings in Evans' boxes. Pedobiologia 51, 343-349.

Huang, D., Todd, P. A. \& Guest, J. R. 2007: Movement and aggregation in the fluted giant clam (Tridacna squamosa L.). J. Exp. Mar. Biol. Ecol. 342, 269-281.

Jeanson, R. \& Deneubourg, J. L. 2009: Positive feedback, convergent collective patterns and social transitions in arthropods. In: Organization of Insect Societies: From Genome to Sociocomplexity (Gadau, J. \& Fewell, J., eds). Harvard Univ. Press, Harvard, pp. 460482. 
Published in : Ethology (2010)

Status : Postprint (Author's version)

Jiang, X. C., Wang, D. \& Halpern, M. 1989: Isolation and characterization of alarm pheromone from electric shock-induced earthworm secretion. Pharmacol. Biochem. Behav. 34, 213-221.

Jouquet, P., Mery, T., Rouland, C. \& Lepage, M. 2003: Modulated effect of the termite Ancistrotermes cavithorax (Isoptera, macrotermitinae) on soil properties according to the structures built. Sociobiology 42, 403-412.

Kammenga, J. E., Spurgeon, D. J., Svendsen, C. \& Weeks, J. M. 2003: Explaining density-dependent regulation in earthworm populations using life-history analysis. Oikos 100, 89-95.

Krause, J. \& Ruxton, D. 2002: Living in Groups. Oxford Univ. Press, Oxford, UK.

Lee, K. E. 1985: Earthworms: Their Ecology and Relationships with Soil and Land Use. London Academic Press, London.

Loeb, J. 1973: Comparative Physiology of the Brain and Comparative Psychology. Ayer Publishing, Manchester, NH.

Lowe, C. N. \& Butt, K. R. 2002: Growth of hatchling earthworms in the presence of adults: interactions in laboratory culture. Biol. Fertil. Soils 35, 204-209.

Mikheyev, A. S. \& Tschinkel, W. R. 2004: Nest architecture of the ant Formica pallidefulva: structure, costs and rules of excavation. Insect. Soc. $51,30-36$.

Nuutinen, V. \& Butt, K. R. 1997: The mating behaviour of the earthworm Lumbricus terrestris (Oligochaeta: Lumbricidae). J. Zool. London $242,783-798$.

Pizl, V. \& Novakova, A. 2003: Interactions between microfungi and Eisenia andrei (Oligochaeta) during cattle manure vermicomposting. Pedobiologia 47, 895-899.

Rasmann, S., Kollner, T. G., Degenhardt, J., Hiltpold, I., Toepfer, S., Kuhlmann, U., Gershenzon, J. \& Turlings, T. C. J. 2005: Recruitment of entomopathogenic nematodes by insect-damaged maize roots. Nature 434, 732-737.

Ratner, S. V. \& Boice, R. 1971: Behavioral characteristics and functions of pheromone of earthworms. Psychol. Rec. 21, 363-371.

Reinecke, A. J. \& Viljoen, S. A. 1990: The influence of worm density on growth and cocoon production of the compost worm Eisenia fetida (Oligochaeta). Rev. Ecol. Biol. Sol. 27, 1-10.

Ressler, R. H., Cialdini, R. B., Ghoca, M. L. \& S., K. 1968: Alarm pheromone in the earthworm Lumbricus terrestris. Science 161, 597-599.

Rombke, J., Jansch, S. \& Didden, W. 2005: The use of earthworms in ecological soil classification and assessment concepts. Ecotoxicol. Environ. Saf. 62, 249-265.

Rosenkoetter, J. S. \& Boice, R. 1975: Earthworm pheromone and T-maze performance. J. Comp. Physiol. Psychol. 88, 904-910.

Salmon, S. \& Ponge, J.-F. 2001: Earthworm excreta attract soil springtails: laboratory experiments on Heteromurus nitidus (Collembola: Entomobryidae). Soil Biol. Biochem. 33, 1959-1969.

Schmidt, H. J. 1955: Behaviour of two species worms in the same maze. Science 121, 341-342.

Sempo, G., Canonge, S., Detrain, C. \& Deneubourg, J. L. 2009: Complex dynamics based on a quorum: decision-making process by cockroaches in a patchy environment. Ethology 115, 1150-1161.

Simpson, S. J., Sword, G. A., Lorch, P. D. \& Couzin, I. D. 2006: Cannibal crickets on a forced march for protein and salt. Proc. Natl. Acad. Sci. USA 103, 4152-4152.

Stephens, P. A., Sutherland, W. J. \& Freckleton, R. P. 1999: What is the Allee effect? Oikos 87, 185-190.

Tschinkel, W. R. 2005: The nest architecture of the ant, Camponotus socius. J. Insect Sci. 5, 9.

Uvarov, A. V. 2009: Inter- and intraspecific interactions in lumbricid earthworms: their role for earthworm performance and ecosystem functioning. Pedobiologia 53, 1-27.

Uvarov, A. V. \& Scheu, S. 2004: Effects of density and temperature regime on respiratory activity of the epigeic earthworm species Lumbricus rubellus and Dendrobaena octaedra (Lumbricidae). Eur. J. Soil Biol. 40, 163-167.

Wertheim, B., van Baalen, E.-J. A., Dicke, M. \& Vet, L. E. M. 2005: Pheromone-mediated aggregation in non-social arthropods: an evolutionary ecological perspective. Ann. Rev. Entomol. 50, 321-346. 
Published in : Ethology (2010)

Status : Postprint (Author's version)

\section{Supporting Information}

Additional Supporting Information may be found in the online version of this article:

Data 1. Equation to describe earthworms; interaction.

Please note: Wiley-Blackwell are not responsible for the content or functionality of any supporting materials supplied by the authors. Any queries (other than missing material) should be directed to the corresponding author for the article. 